ANNOUNCEMENT

\section{Best Paper Award}

(c) ASM International 2017

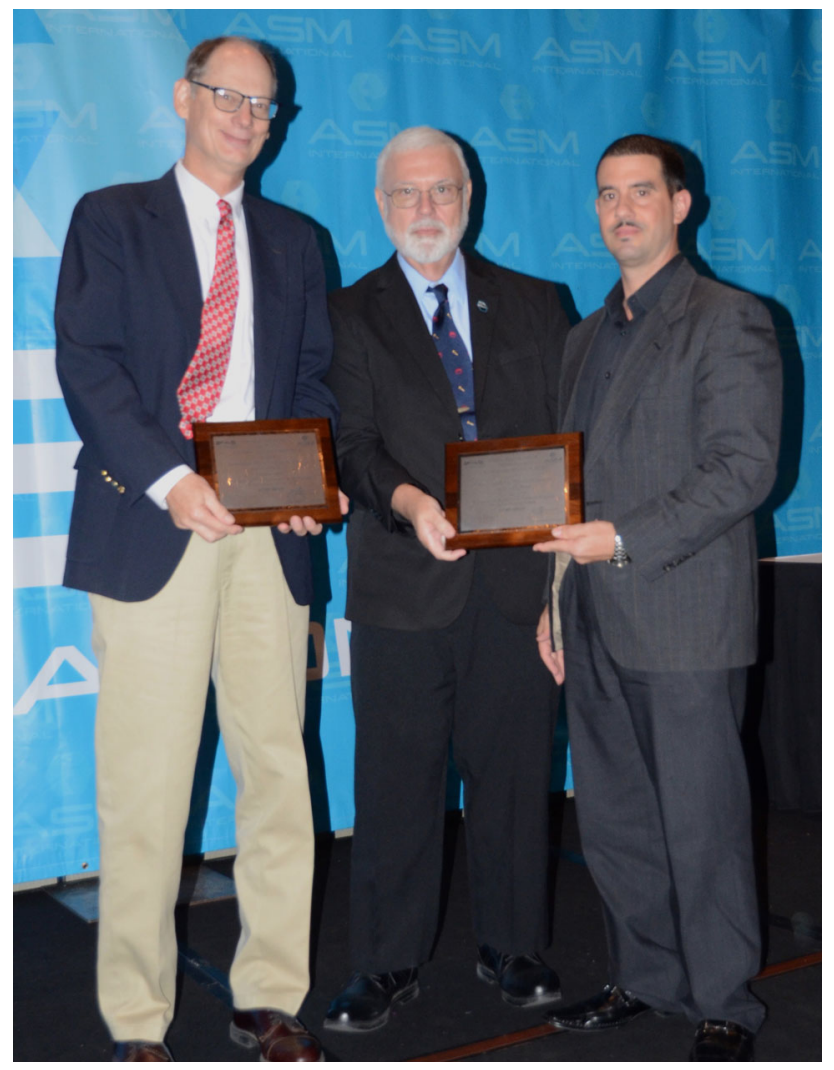

William Frazier, President, ASM International (middle), presents the Volume 16 JFAP Best Paper Award plaques to Daniel J. Benac (left) and David Wood (right) during MS\&T '17.
Dr. Michael E. Stevenson, editor of the Journal of Failure Analysis and Prevention (JFAP), announced that the JFAP Volume 16 Best Paper is "Managing Cold Temperature and Brittle Fracture Hazards in Pressure Vessels" by Daniel J. Benac, Nicholas Cherolis, and David Wood. The winning article was published in the February 2016 issue of JFAP.

The award, in addition to the recognition, includes a plaque and $\$ 1000$ worth of ASM International products and services. The Best Paper was selected by the Editorial Board of the journal from all papers published in volume 16 . 